\title{
TECNOLOGIAS DIGITAIS, TEMPOS DE PANDEMIA E O ENSINO DE MATEMÁTICA: EDUCAÇÃO TECNOLÓGICA EM PERSPECTIVA
}

\section{DIGITAL TECHNOLOGIES, PANDEMIC TIMES AND THE TEACHING OF MATHEMATICS: TECHNOLOGICAL EDUCATION IN PERSPECTIVE}

\author{
Josiel de Oliveira Batista ${ }^{1}$ \\ Nelem Orlowski ${ }^{2}$ \\ Eder Paulo Pereira ${ }^{3}$ \\ Tânia Mara Vitaczik Campanucci ${ }^{4}$ \\ Luciane Ferreira Mocrosky $^{5}$
}

\begin{abstract}
Resumo: Neste texto são explicitados indicativos para articular um diálogo frente ao novo cenário educacional que o ensino da matemática está atravessando com a pandemia causada pelo vírus SARS-CoV2, desencadeada no ano de 2019. Tematizam-se compreensões acerca das tecnologias digitais para o ensino de matemática e discutem-se isso pelo viés da perplexidade que se tem vivido ao habitar o mundo tecnológico em meio a uma situação de pandemia declarada. Para isso, procurou-se pela escuta atenta do momento vivido vislumbrar possibilidades que se abrem para o ensino de matemática com tecnologias, tendo como solo de compreensão o habitar heideggeriano. Conclui-se a centralidade do ser-com-o-outro como essencial para a educação, requerendo modos diferentes de pensar, de formar pessoas e de formar-se professor.
\end{abstract}

Palavras-chave: Educação Matemática; Tecnologias digitais; Pandemia; Habitar.

\begin{abstract}
This text provides indications for articulating a dialogue in the face of the new educational scenario that the teaching of mathematics is going through with the pandemic caused by the SARS-CoV-2 virus, unleashed in 2019. Understandings about digital technologies for the teaching of mathematics are discussed and this is discussed due to the perplexity that has been experienced when inhabiting the technological world in the midst of a declared pandemic situation. For this, we tried, through attentive listening to the lived moment, to glimpse possibilities that open up for the teaching of mathematics with technologies, having Heidegger's inhabitance as the soil of understanding. It concludes the centrality of being-with-the-other as essential in education, requiring different ways of thinking, of forming people and of becoming a teacher.
\end{abstract}

Keywords: Mathematical Education; Digital technologies; Pandemic; Dwell.

\footnotetext{
${ }^{1}$ Doutorando pela Universidade Federal do Paraná (UFPR). Professor na Universidade Federal do Sul e Sudeste do Pará (UNIFESSPA), Marabá, Pará, Brasil. E-mail: josieloliveira@ unifesspa.edu.br

${ }^{2}$ Doutoranda do Programa de Pós-Graduação em Formação Científica, Educacional e Tecnológica (PPGFCET) da Universidade Tecnológica Federal do Paraná - Câmpus de Curitiba (UFPR). Professora da Rede Municipal de Ensino de Curitiba, Curitiba, Paraná, Brasil. E-mail: orloviskice@yahoo.com.br

${ }^{3}$ Mestre pela Universidade Federal do Paraná (UFPR). Professor na rede Estadual de Ensino do Paraná, Curitiba, Paraná, Brasil. E-mail: pereiraederpaulo@gmail.com

${ }^{4}$ Mestre pela Universidade Federal do Paraná (UFPR). Professora na Rede Municipal de Ensino de Ensino de Curitiba, Curitiba, Paraná, Brasil. E-mail: tamavica@gmail.com

${ }^{5}$ Doutora em Educação Matemática pela Universidade Estadual Paulista - Campus de Rio Claro (UNESP). Professora da Universidade Tecnológica Federal do Paraná e do Programa de Pós-Graduação em Formação Científica, Educacional e Tecnológica (PPGFCET-UTFPR). Curitiba, Paraná, Brasil. E-mail: mocrosky@gemail.com
} 


\section{0 que nos move à procura de uma abertura?}

Ao longo da história, a humanidade vive situações diversas com (des)acertos em busca de ressignificações de espaços, tempos e relações interpessoais. Relações estas permeadas por fatos e fatores que interferem direta ou indiretamente no modo como o homem se compreende no mundo. Para Bicudo (2011a), é na vivência refletida que o ser humano dá "conta das marcas do havido na totalidade de sua historicidade que, necessariamente, traz a dos outros e da vida, possibilitando a interpretação de si e do mundo histórico-cultural" (BICUDO, 2011a, p. 88).

Neste horizonte, o real vivido traz em seu bojo possibilidades para a constituição do ser-no-mundo, pelas reorganizações de cenários e contextos que se estabelecem no cotidiano e no estar com o outro que se desvela em mudanças sociais, climáticas, políticas, ambientais, educacionais, de saúde da população, dentre outros.

Nossa inquietação neste momento nos move a olhar atentamente o que vem permeando nossa cotidianidade na educação entrelaçada com a saúde. Dado o momento histórico em que vivemos, isto é, a pandemia declarada pela Organização Mundial de Saúde $^{6}$ (OMS) e seguindo a orientação desta agência, encontramos-nos em distanciamento social $^{7}$, ou seja, sem aulas presencias.

Desencadeada no ano de 2019, a pandemia causada pelo vírus SARS-CoV-2 se alastrou pelo mundo, forçando novas condições de as pessoas estarem juntas. Nestes últimos meses, vivenciamos as circunstâncias postas no Brasil, desde o primeiro trimestre do ano de 2020, com o distanciamento social causado pela pandemia em atendimento às orientações da OMS (MARTINS; ALMEIDA, 2020; SANTOS, 2020; SANTOS; LIMA, 2020).

Durante esse período, as aulas presenciais foram suspensas e a condição de continuidade do ensino foi constituída pelo uso de recursos tecnológicos que possibilitassem manter a educação ativa. Neste aspecto, em nosso espaço de trabalho, vimos buscando por compreensões do vivido. Focamos, mais especificamente, nossas inquietações sobre o ensino da matemática, marcando que ao interrogarmos o que os inquieta estamos fazendo "um recorte do mundo real vivido, destacando-se no pano de

\footnotetext{
${ }^{6}$ É uma agência especializada das Nações Unidas, destinada às questões relativas à saúde. Tem como objetivo garantir o grau mais alto de saúde para todos os seres humanos.

${ }^{7}$ Para a OMS, distanciamento social é a diminuição de interação entre as pessoas de uma comunidade para diminuir a velocidade de transmissão do vírus.
} 
fundo da compreensão existencial aquilo sobre o que se quer saber" (BICUDO, 1992, p. $8)$.

No entanto, a estratégia adotada por muitas escolas em usar recursos tecnológicos disponíveis em tempos de aulas não presenciais também revelou uma lacuna. Não podemos negar que quando o foco incide sobre ter acesso às Tecnologias Digitais ${ }^{8}$ (TD), fragilidades na educação brasileira são evidenciadas, por exemplo, pela exclusão dos estudantes, principalmente nas redes de ensino públicas, ao direito de acesso à educação. Esta situação, por si só, constituir-se-ia na inviabilização do ensino remoto, uma vez que atinge os pilares que caracterizam a educação enquanto direito público.

A educação pública e gratuita, garantida na Constituição de 1988 como direito de todos e dever do estado, da sociedade e da família, apresenta agora sua face de fragilidade ao revelar um grande quantitativo de excluídos digitais, evidenciados pela supressão de milhares de alunos do processo educativo, por não possuírem acesso às TD que os possibilitariam interagir nesse novo espaço escolar. Situação semelhante também aconteceu com o professor por meio dos desencontros deste profissional com as TD. Essa nova configuração pegou de surpresa diversos professores, com acentuadas dificuldades em manusear equipamentos digitais e fazer deles instrumentos para desenvolver novos modos de ensinar em espaços virtuais de aprendizagem (BEZERRA; VELOSO; RIBEIRO, 2021).

Como única possibilidade disponível, as redes de ensino públicas e particulares se debruçam a viabilizar a continuidade do ensino pelas mãos de diferentes recursos tecnológicos (canais de televisão, salas virtuais, aplicativos, dispositivos móveis, etc.). Professores de todo país se veem de um momento para o outro, completamente imersos em uma circunstância em que, além do ensino, precisaram pensar em como ensinar com a tecnologia, para adequarem-se a um "novo normal" (ENGELBRECH, J. et al., 2020, p. 02). Aprendemos no isolamento que a possibilidade da tecnologia veicular aulas, pelo modo como leva a escola para as casas, tem se mostrado na linha de frente da educação, velando perspectivas de pensamento constituído pelos modos como vimos sendo na sociedade cada vez mais denominada tecnológica.

Tal como em Henrique (2020), há um "isolamento social físico" ao mesmo tempo em que se intensifica a comunicação via tecnologia, uma vez que nosso convívio e

\footnotetext{
${ }^{8}$ Obata, Mocrosky e Kalinke (2018) diz que TD são caracterizadas por diversos aspectos da chamada multimodalidade, como por exemplo, internet, interatividade, tecnologia móvel, entre outros elementos tecnológicos.
} 
práticas diárias, sejam pedagógicas ou sociais, foram reinventadas e não paralisadas. Assim, a escola em casa ganha mais vulto do que aprender em todos os lugares e com tudo que conosco habitam o mundo.

Neste novo formato de repensar a Educação e realizá-la, a formação do professor também vem sendo requisitada de formas diferentes. O que ensinar e como ensinar vem movimentando o imaginário docente e, consequentemente, tem sinalizado a busca por suporte para sua formação para além de aspectos tecnológicos, considerando que cada sistema de educação estabeleceu também seus modos de ação. Neste cenário, os professores, por necessidade, viram-se e se sentiram buscando diariamente modos de fazer o ensino acontecer, ou seja, viram-se em formação vivenciando diariamente a responsabilidade de suas escolhas e ações, por serem propulsoras do o quê e o do como a educação seria possível.

Esse novo modo de fazer a educação extrapolou complementarmente a institucionalização de modelos e da racionalidade técnica, sendo solicitada quase como um modo de sobrevivência docente e do próprio ensino. Sem tempo e sem preparação adequada, mostrou-nos que a educação e, consequentemente, a educação matemática, requeriam a necessidade da ampla utilização, conhecimento e domínio de toda a tecnologia disponível.

A presença das TD no ambiente escolar não era considerada uma novidade, uma vez que por diversas facetas essas ferramentas permeavam o dia a dia dos atores desse cenário escolar, seja por meio de celulares, datashow, blogs, etc. No entanto, o que observamos foi um abismo entre o (sobre)viver e o habitar, que nos mostrou que talvez o mais difícil e o mais estranho para nós educadores matemáticos tenha sido admitir que o tecnológico se precipitou e chegou antes que pudéssemos prever como lidar com ele, mesmo que estivéssemos discutindo há anos novos objetivos para a educação. Objetivos estes que, apesar de amplos e gerais, refletiam os rumos de nossa sociedade com seus novos estilos de produção, oportunidades de trabalho e sobretudo a rapidez e a intensidade de produção e constituição de conhecimento e, consequentemente, modos diferentes de pensar, de formar pessoas e de formar-se professor.

Essa preocupação com a formação das pessoas numa perspectiva da educação tecnológica na educação matemática é levantada por Mocrosky, Mondini e Orlowski (2020, p. 02) ao relatarem que "há uma cadência linear que destaca as TD como um produto, sustentando a formulação de um discurso que enfatiza o quanto a falta interfere, dificultando que a formação docente reflita na prática pedagógica”. No entanto, pela falta 
ou pela imposição, a tecnologia se fez presença, causando-nos perplexidade, colocandonos em estranhamento com os próprios modos de continuarmos educando, ao mesmo tempo em que se abriram muitas possibilidades para repensarmos o exercício da própria docência, de como estar educando com as TD.

Destas inquietações, permanece pulsando em nossos estudos no Grupo de Estudos e Pesquisa em Formação de Professores (GEForProf) a interrogação: que possibilidades se revelam para um ensino da matemática com as TD em ambientes virtuais, em tempos de distanciamento social? Essa interrogação é permeada por algumas perguntas de fundo: como ser-com-outro em um momento de distanciamento social? Como ensinar matemática não estando junto ao outro? As TD anunciadas em ambientes virtuais podem ser um caminho para o encontro ensino-professor-estudante? Por que, mesmo estando em uma sociedade tecnológica, demonstramos estranhamentos quando nos colocamos a ensinar matemática com as TD? O uso das TD abre possibilidades para o cuidado e a escuta do estudante?

Para Heidegger (2005), o ser-no-mundo, que se constitui enquanto ser-com-osoutros, realiza possibilidades no mundo circundante. Isso implica considerar que só somos-com-os-outros (compreendemos e significamos o mundo, a linguagem e a escola estando junto com tudo e todos com os quais habitamos o mundo). É com a possibilidade do outro que a tecnologia cria aberturas para um ser-com-o-outro, ser-junto, estar-como-outro e para estas reflexões no campo do ensino, do aprender-com-o-outro, mesmo em ambientes físicos/temporais diferenciados.

$\mathrm{Na}$ esteira deste estudo, compreendemos o ser-com-o-outro como

[...] possibilidades de o ser-humano-ser-com-o-outro, ainda assumindo a concepção heideggeriana de compreender o ser humano como feixe de possibilidade abertas ao aí, que é o espaço em que "o com" está presente, atualizam-se pelas escolhas efetuadas. Estas nunca são decorrentes de um indivíduo fechado em si, mas, sempre realizadas pela sua característica existencial de ser com o outro no aí, ou seja, na abertura da espacialidade. As escolhas, ao serem atualizadas, materializam situações, elas próprias contextualizadas na espacialidade e na historicidade que estruturam o aí e que se movimentam junto com o modo de ser do ser humano (BICUDO, 2010, p. 129).

Conforme Rosa (2015), entendemos que o ser-com revela neste contexto de um ensino com tecnologias, um ser-com-as-tecnologias nos aspectos de pensar-com e fazercom. Buscando por aberturas, mas sem a pretensão de esgotar aqui discussões e possibilidades, tampouco oferecer modelos que tragam uniformidade de caminhos a serem seguidos, intencionamos trazer indicativos, procurar abrir frestas de luz para estabelecer o diálogo neste novo cenário educacional possível para o ensino da 
matemática. O que buscamos são compreensões acerca das tecnologias digitais para o ensino de matemática que se intensificaram em tempos de pandemia e discutimos isso pelo viés da perplexidade que temos vivido ao habitar essas tecnologias em meio a uma situação de pandemia declarada. Para isso, procuramos, por meio da escuta atenta do momento vivido, compreender possibilidades que se abrem para o ensino de matemática com tecnologias, no horizonte do habitar heideggeriano.

\section{0 habitar: nossa necessidade de brechas para conviver no mundo tecnológico da educação}

Na sociedade contemporânea, diariamente somos expostos a novos desafios, encontros e desencontros em nossas vidas, dentre outros elementos que cotidianamente estão a surpreender-nos, como o atual distanciamento social causado pela pandemia declarada pela OMS. Estes desafios também se estendem ao sistema de ensino e à educação matemática, tendo nas TD e seus ambientes virtuais uma possibilidade de juntar professores e estudantes, mesmo separados por um distanciamento físico e geográfico.

Tomados dessa forma, espaço e tempo são delineados por meio da interação entre todos os envolvidos no processo efetivo de ensino e aprendizagem, pois “o foco não está na quantidade de horas presenciais, mas na possibilidade de interação a distância entre os atores do processo, mediante a tecnologia" (BORBA; MALHEIROS; AMARAL, 2011, p. 25). Nesta nova forma de concepção do conhecimento, “o 'tempo' que se constitui para a comunicação nas redes sociais é definido pelos sujeitos não precisando estar juntos em mesmo tempo cronológico" (FERREIRA, 2014, p. 62) e, dessa forma, a construção do conhecimento é dado de acordo com o espaço e o tempo do estudante, em consonância com o planejado pelo professor.

Neste cenário, interrogamos: que possibilidades de ser-com-o-outro (ser junto e à distância) se abrem com as TD como articuladoras desse encontro? Considerando o nosso contexto de experiências vividas como professores, voltamos a nos interrogar frente a este novo cenário: como ensinar matemática não estando junto ao outro? Como ensinar matemática sem o espaço escolar físico e cronológico que conhecemos?

Considerando que estamos imersos em uma sociedade cada vez mais informatizada e tecnológica, a escola não está alheia a isto e sim cada vez mais envolta neste movimento, em que a aparatos tecnológicos (celulares, internet, computadores, tablets, dentre outros) se constituem como presença constante neste universo das TD nas 
escolas. Para Borba e Penteado (2016), somos considerados seres-humanos-com-mídias, devido à presença indissociável da tecnologia no cotidiano do homem contemporâneo. Podemos também pensar, como aponta Rosa (2015), que somos um ser-com-tecnologias.

Nesta realidade nova em apresentação, vemo-nos cercados por estranhamentos e interrogações, como por exemplo: como nos vemos nessa organização de pensar a educação, considerando nossa condição de sermos no mundo tecnológico, na busca do estar-junto, do aprender-junto e ensinar-junto, mesmo estando a distância?

Para Heidegger (2005), o pilar da existência é como este homem se compreende como um ser-no-mundo. A existência é pautada no "aí no mundo" que se vive junto com os outros e nos modos como nos compreendemos sendo um ser-no-mundo, um ser que o habita. Ser este que já nos pressupõe uma outra reflexão, que é a de como este homem habita este mundo. Podemos ir além, quando nos inquietamos e voltamos a interrogarnos: como este homem pode então habitar este mundo tecnológico? O que significa habitar? Como é possível habitar?

Partilhamos da concepção de habitar apresentada por Mocrosky, Mondini e Orlowski (2020), enquanto Ser que existe e, portanto, habita no mundo tal como ele é, tecnológico. As autoras compreendem que o habitar, além do co-pertencer num mesmo espaço Ser e TD, insere-se na condição de permanência e de envolvimento deste Ser com as TD, superando uma concepção utilitarista

\footnotetext{
Quando trazemos o verbo habitar, fundamentado nas obras heideggerianas, para falar das Tecnologias Digitais no formar e formar-se - numa perspectiva da Educação Matemática - temos a intenção de apresentá-las como um permanecer, em que há envolvimento para além do utilitarismo (MOCROSKY; MONDINI; ORLOWSKI, 2020, p. 164, tradução nossa).
}

Para Heidegger (2008), o habitar suplanta possuir uma residência, uma construção, ou então estar morando em um lugar construído, pois nem toda construção configura uma residência tal qual a conhecemos. Mas mesmo estas construções podem ser habitadas na compreensão heideggeriana, se pensarmos o habitar como além de possuir uma simples residência.

Realizando aproximações com o pensar heideggeriano, podemos citar uma escola, que é uma construção realizada através do tempo pelas mãos do homem, mas esta não se configura em uma residência no que conhecemos por residência no sentido de edificações, mas pode tornar-se o habitar-do-homem, ou seja, um local onde o professor sente-se em casa, sente-se protegido, sente-se familiarizado e, mesmo assim, estranha-se entre as 
coisas. Mesmo a escola não sendo uma residência, o professor pode habitar esta construção institucional.

Habitar significa como o homem se relaciona com os espaços em seu entorno, com esse ser-no-mundo-que-o-cerca: "o habitar não significa apenas um estar geometricamente ao lado do objeto - nem mesmo esse habitar implica necessariamente a proximidade físico-matemática" (PITTA, 2016, p. 64). Ainda nesta compreensão

\begin{abstract}
O habitar não se refere simplesmente ao fato de se possuir uma residência, mas traduz-se no modo como o homem, ao se relacionar com suas possibilidades de ser-no-mundo (através, da tecnologia que o possibilita construir uma ponte, um hangar, um estádio, uma usina elétrica, etc.) constrói o mundo que o circunda (JESUS; RIBEIRO, 2007, p. 2).
\end{abstract}

Pelo iniciado neste texto, podemos pensar que só o construído por nós tem condição de ser habitado. Do mesmo modo, podemos perguntar se todas a construções são, por assim dizer, habitáveis. Heidegger (2002), em "Ser e Tempo", discute as ideias do habitar e do construir, exemplificando-as por situações cotidianas. Mesmo que os estudos heideggerrianos não sejam dirigidos à educação escolar, possibilitam-nos aberturas para compreensões no contexto educacional. Esse filósofo nos provoca a pensar sobre construir e habitar, dizendo:

Uma ponte, um hangar, um estádio, uma usina elétrica são construções e não habitações: a estação ferroviária, a auto-estrada, a represa, o mercado são construções e não habitações. Na auto-estrada, o motorista de caminhão está em casa, embora ali não seja a sua residência; na tecelagem, a tecelã está em casa, mesmo não sendo ali a sua habitação. Nelas o homem de certo modo habita e não habita, se por habitar entende-se simplesmente possuir uma residência (HEIDEGGER, 2008, p. 125).

Nesta perspectiva, inspirados no pensamento de Heidegger de construir e habitar, e realizando aproximações com a escola, podemos compreender que os espaços de ensino, sejam eles físicos ou virtuais, podem configurar-se como uma construção e uma habitação. Da mesma maneira, o professor pode habitar com a tecnologia que está à sua disposição realizando suas práticas pedagógicas com o ensino da matemática por meio destas, entendendo que o habitar "não se restringe a possuir uma residência, mas é a própria condição em que o homem se encontra no mundo" (JESUS; RIBEIRO, 2007, p. 4). É, ainda, "no sentido de ser e estar sobre a terra" (HEIDEGGER, 2008, p. 127).

Assim, voltamos a interrogar-nos sobre a possibilidade de as TD com seus ambientes virtuais estarem junto ao homem neste momento de distanciamento social e, no caso deste estudo, as TD representadas por ambientes virtuais como um possível caminho para ensinar matemática em tempos e espaços diferenciados. Cabe lembrar que 
nesse cenário o ensino e a aprendizagem são mediados por relações que transcendem o espaço-tempo físico, uma vez que

O uso de computadores e da internet no ambiente escolar proporcionou uma revolução com proporções inimagináveis, pelas formas diversas de comunicação e de ensino, democratizando o acesso a todos à educação ao modificar a concepção de espaço e de tempo num ambiente de aprendizagem (BATISTA, 2016, p. 8).

Segundo Heidegger (2008), a palavra do antigo alto-alemão "buan" é bastante utilizada para indicar a palavra construir, porém seu significado também se traduz no habitar, remetendo-nos às compreensões de que ambas as palavras, construir e habitar, estão intimamente ligadas desde seu princípio. Então, qual nosso estranhamento em habitar algo que se presentifica no nosso dia a dia? E no caso deste estudo, qual o estranhamento em habitar as TD? Para o autor, com o passar do tempo fomos distanciando-nos destas duas palavras (construir e habitar), criando entre elas um espaço que, originalmente, ambas não possuem. Passamos a atribuir sentidos e significados, muitas vezes opostos a estes dois termos, que, desde sua concepção original, sempre estiveram unidos de maneira muito íntima, mas sem perderem sua identidade em cada caso. O que levou a isto?

Em nosso cotidiano, ocorre uma supressão de alguns termos que não ficam em um primeiro plano. No caso "buan", o construir fica muito mais em evidência do que o habitar, devido a uma questão de uso da linguagem. Linguagem esta, apoiada muitas vezes no que os olhos podem ver, ou seja, as construções são visíveis, enquanto o habitar não. O habitar pode ser aqui uma possível sinalização do motivo do construir sobreporse ao habitar, pois como já mencionado, a palavra "buan" era usada para dizer construir, mas também possui o significado de habitar. Significado este que foi perdendo-se com o passar dos tempos, ficando este habitar em um segundo plano da linguagem, e por consequência um distanciamento entre ambos, um silenciamento da conexão entre o construir e o habitar "buan".

Neste sentido, Heidegger (2008) nos relembra que

Nas palavras essenciais da linguagem, o que elas se dizem propriamente cai, com muita facilidade, no esquecimento, em favor do que se diz em primeiro plano. $\mathrm{O}$ homem ainda não chegou a pensar o mistério desse processo. A linguagem retrai para o homem o seu dizer simples e elevado. Mas isso não chega a emudecer o seu apelo inicial. $\mathrm{O}$ apelo apenas silencia. $\mathrm{O}$ homem não presta atenção a esse silêncio (HEIDEGGER, 2008, p. 128).

\footnotetext{
${ }^{9}$ Conforme dicionário online Michaeles: “Alto-alemão antigo, LING: denominação geral para os vários dialetos germânicos que eram falados em algumas regiões do sul da Alemanha, bem como na Áustria e Suíça até o final do século XI; alemão antigo". Disponível em: < http://michaelis.uol.com.br/busca?id=yLPG>. Acesso em: 30 jan. 2021.
} 
Reforçando ainda mais a importância deste movimento de sincronia entre o construir e o habitar em torno da linguagem e deste reconhecimento do homem-nomundo-que-o-cerca, compreendemos que

\begin{abstract}
Enquanto não pensarmos que todo construir é em si mesmo um habitar, não poderemos nem uma só vez questionar de maneira suficiente e muito menos decidir de modo apropriado o que o construir de construções é em seu vigor de essência. Não habitamos porque construímos. Ao contrário. Construímos e chegamos a construir a medida que habitamos, ou seja, a medida que somos como aqueles que habitam (HEIDEGGER, 2008, p. 128).
\end{abstract}

O que podemos observar é que quando pensamos em construir já estaríamos habitando este lugar, pois "construir é propriamente habitar" (MENDES, 2009, p. 197), construindo então uma relação única entre estes dois termos apresentados, e ainda compreendendo que "o habitar abrange, na verdade, todas as formas pelas quais o homem constrói o mundo onde vive (SALDANHA; KLAUTAU, 2016, p. 149).

Assumimos, assim, a postura de uma educação tecnológica permeada pela existência de TD, que têm na própria tecnologia a opção de formar pessoas com o uso de tecnologias diversas, em que esse aparato se mostra mais como um aliado ao ensino do que como uma condição necessária para este. Esse modo de compreender o uso de tecnologias pela educação é apontado por Mocrosky, Mondini e Orlowski (2020, p. 160) ao relatar que "ao olharmos a Educação Tecnológica pelas lentes da formação das pessoas, nos afastamos de defini-la como algo que se coloca à disposição da educação escolar, assim como qualquer tecnologia educacional que enfatiza recursos disponíveis que se pode ou não lançar mão.”

Nossa preocupação é com o cuidado e com a escuta que se alicerça em uma nova situação de exclusão digital que nossa sociedade vem experimentando. A situação é semelhante ao processo de invisibilidade que pessoas analfabetas vivenciam ao se verem privadas em situações diversas que exigem leitura e interpretação como forma de presentificar-se ou de estar com as diversas formas que o mundo contemporâneo se mostra aos homens por meio das TD. A analogia que fazemos com a situação do analfabetismo que o país ainda enfrenta, seja por meio do analfabetismo estrutural, seja pelo funcional, justifica-se pela impossibilidade de milhares de crianças usufruírem do direito básico de acesso à educação, por não serem alfabetizadas tecnologicamente ou por não possuírem condições de acesso à essas tecnologias. 


\section{Uma crise do habitar? Articulações necessárias para construções serem habitadas no mundo tecnológico}

Neste contexto, tecnológico, construído e constituído pelas mãos do homem, percebemos um distanciamento destas TD exatamente no momento em que o homem necessita mais destas em sua vida. Por que este estranhamento das TD que o homem construiu, se o próprio homem vem apontando indícios de que não vem conseguindo habitá-las? Será uma crise do construir e do habitar?

Podemos buscar esclarecimentos para esses questionamentos a partir de exemplos, como as relações estabelecidas entre o espaço escolar, os equipamentos tecnológicos que compõem e os seres que transitam nesse espaço e fazem dele um ambiente de convivência, trabalho, aprendizagem etc. Observamos que, muitas vezes, esse espaço possui grande quantidade de equipamentos e recursos tecnológicos que foram construções do homem, mas que muitos não as utilizam em seu fazer pedagógico.

Uma resposta para essa problemática seria partir do entendimento da multiplicidade que compõe o humano e o universo particular que existe em cada ser, tornando-nos únicos dentro de espaços de convivência e conveniência mútuos. Apesar de sermos iguais, somos diferentes na unimultiplicidade que compõe cada um de nós. Deste modo, a escolha pela profissão professor não carrega consigo a obrigatoriedade de manipular com destreza TD, mas carrega a necessidade de aprender a manuseá-la, tomando por base sua presença no ambiente escolar.

Em nosso contexto atual de distanciamento social, em que o ensino clama por caminhos de aproximação entre professor e estudante, no sentido de estar junto-com-ooutro, temos tentado habitar os espaços de ensino virtuais, construções estas já feitas pelo homem há tempos. No entanto, o que vemos é a fragilidade na articulação entre o ensino da matemática e a relação professor-estudante em um ambiente não presencial.

Alicerçados nos pensamentos heideggerianos de construir e habitar, vemos um possível distanciamento em construir e habitar quando endereçadas às práticas de ensino com as TD. Por que ocorre este distanciamento? Por que o mesmo homem que constrói não necessariamente habita suas construções e, do mesmo modo, o habitar não é exclusividade do construtor? Por que existe a dificuldade no homem de habitar o mundo tecnológico, visto que tecnologias são construções idealizadas pelo próprio homem? Estas questões podem estar sinalizando para uma ruptura entre o construir e o habitar, que podemos chamar de "crise do habitar" (DILNOT, 2009, p. 205). 
A crise do habitar é aqui entendida muito além da crise habitacional presente em nossa contemporaneidade, estando centrada em um reconhecimento deste homem neste mundo, um reconhecimento do habitar, um reconhecimento do eu-no-mundo.

\begin{abstract}
Por mais difícil e angustiante, por mais avassaladora e ameaçadora que seja a falta de habitação, a crise propriamente dita do habitar não se encontra, primordialmente, na falta de habitações... A crise propriamente dita do habitar consiste em que os mortais precisam sempre de novo buscar a essência do habitar, consiste em que os mortais devem primeiro aprender a habitar (HEIDEGGER, 2008, p. 140).
\end{abstract}

Este distanciamento entre o construir e o habitar pode causar um não reconhecimento deste lugar onde o homem habita e, por consequência, uma dificuldade em encontrar-se como ser-no-mundo, assim como de compreender as diversas nuances que o habitar possui. Guiados pelos pensamentos de Heidegger, voltamos a perguntarnos: mas por que o mesmo homem que está em contato direto com as TD tem encontrado dificuldades em habitar este mundo tecnológico?

Podemos fazer um exercício na tentativa da compreensão do exposto, partindo de uma ideia equivocada de que o habitar seja correlato ao construir, em que necessariamente quem constrói algo físico, o habita. Partindo desse pressuposto em direção a este estudo, no momento em que o homem constrói estas TD, deveria habitar estas construções, estabelecendo a relação entre construir-habitar. No entanto, quando observamos a escola, as TD e os ambientes virtuais, enveredamos pelos caminhos da formação de pessoas com o uso de tecnologias, pois quando estamos no âmbito de formar pessoas não basta essa perspectiva utilitária e técnica da tecnologia, há a necessidade de existir com ela, no sentido de compreender-se com ela, de Ser-com-as-TD.

Quando trazemos o termo habitar no mundo tecnológico, fundamentado nas obras heideggerianas, não estamos referindo-nos unicamente aos sujeitos que produzem TD, mas por todos os que convivem com este aparato tecnológico e o co-habitam no sentido lógico, humano. Podemos pensar que este professor que habitará este mundo tecnológico muitas vezes não é o mesmo homem que construiu tais tecnologias, fazendo-nos refletir que o ato de construir não se resume ao edificar algo tangível. Diz de racionalidade, de modos de trazer as coisas à razão, portanto, uma construção erguida com intencionalidade e planejamento na busca do ser-no-mundo, ou ainda, um permanecer em que há envolvimento para além do utilitarismo e da exibição de um feito.

Então, para além da "crise do habitar", temos estes desencontros entre professor e tecnologia em ambientes virtuais, o que nos faz permanecer muitas vezes alheios ao movimento tecnologia-sociedade-escola. Esse distanciamento vem causando, por vezes, 
estranhamento do professor no que se refere às TD, mesmo que estas já estejam há algum tempo presentes em seus cotidianos, mas que agora foram intensamente lançadas em seu fazer docente.

Podemos pensar que o professor pode não sentir-se familiarizado com as TD em suas práticas de ensino da matemática, por ele não habitar este mundo tecnológico, mesmo quando estas se encontram presentes em seus espaços, levando-nos a pensar em um contraponto ao habitar, que "mais do que habitar, era preciso pensar no seu oposto, o 'não sentir em casa' pelo ser-no-mundo" (SARAMAGO, 2011, p. 75).

Compreendemos que a perplexidade só pode ser compreendida se vivida com atenção, uma vez que

Habitar diz primeiro do habitual, do que comparece com frequência e está na estrutura da tradição do fazer humano. Imersos no cotiando, o homem se lança em caminhadas, muitas vezes sem questionar as coisas ou se questionar sobre elas. A familiaridade que se tem com as coisas conduz um modo de habitar humano. Entretanto, o familiar, o habitual, traz em si aberturas para estranhamentos, que acontecem quando na vivência com o familiar algo nos incomoda, nos provoca, nos convoca a olhar para além do que aparece. Essa perplexidade nos coloca em estado de alerta, de atenção, de atentividade e, assim, o estranhar-se com e nas coisas se dispõe como uma condição de abertura para o conhecimento, para o deixar-habitar (MOCROSKY; MONDINI; ORLOWSKI, 2020, p. 162-163, tradução nossa).

Esta questão de não sentir-se em casa, como mencionado por Saramago (2011), trazendo um estranhamento e por consequência um distanciamento do professor para com o mundo tecnológico, pode ser traduzido pelos desencontros de gerações que co-habitam o espaço escolar.

Neste contexto, faz-se necessário um re-pensar deste habitar do professor ao mundo tecnológico, refletindo que este pode estar familiarizado com as TD e os ambientes virtuais que estão à sua disposição, pela urgência de que este professor assuma a docência em tempos de distanciamento social para o desenvolvimento de sua prática de ensino. Assim, faz-se imperioso um retorno do professor ao tecnológico, não bastando neste momento apenas habitar, mas a possibilidade de fazer morada neste mundo tecnológico frente à esta nova demanda educativa.

Dispondo-nos às aberturas que vivenciamos neste momento de isolamento de modo atento, de modo formativo, lançamo-nos a compreensões para a pergunta: quais possibilidades se revelam para um ensino da matemática com as TD em ambientes virtuais, em tempos de distanciamento social? Este modo formativo nos mostra que se faz necessário e pungente pensar no aspecto excludente de crianças dos novos espaços 
educacionais que se tornaram morada para os participantes do convívio escolar, agora caracterizados pelo estar juntos à distância.

As possibilidades se mostram minguantes no alheamento das autoridades governamentais que têm tratado o assunto como uma excepcionalidade (que o é) e que, portanto, consideram não ter nada a fazer a não ser esperar passar. Revelam alunos e professores que, por não terem escolhas, permanecem perdidos e apagando-se nos desencontros entre TD e o ato de educar.

\section{A urgência em assumir-se sendo em um mundo tecnológico}

Temos constatado diariamente que o cenário mundial de pandemia tem obrigado o professor a ver-se imerso numa nova conjuntura de ensino e de aprendizagem, isso porque uma nova conjuntura de educação se instalou e, a partir de então, as possibilidades que se abriram ao ensino foram a de adaptar-se para ensinar por meio do ambiente virtual. Esta, que se tornou a possibilidade do estar junto mesmo à distância, "não é uma mera condição ocupacional" (BICUDO, 2014, p. 23), mas um modo disponível para educar em tempos de distanciamento social.

Mas e o professor, o que tem feito em relação a essa nova conjuntura educacional? Tem tentado adequar-se a esse novo formato, mesmo que isso aconteça por meio de desencontros. Esses desencontros têm se dado justamente pelo fato de que o professor não tem habitado as $\mathrm{TD}$, no sentido de não possuir domínio sobre elas. Isso tem acontecido porque ele (o professor) não é um criador de TD. Enquanto um ser que não é criador, o que resta para ele é buscar aprender a lidar e a conviver com elas. Certamente não ter TD na escola e não saber usá-las se revela como uma lacuna para o ensino, entretanto, não manifesta a complexidade do tema, haja vista que ter e saber usar nem sempre têm no horizonte o ensino da matemática (MOCROSKY; MONDINI; ORLOWSKI, 2018).

É importante nestas reflexões observarmos que o não sentir-se habitando as TD ao exercer a função docente se revela para além da falta de formação inicial e continuada, ou da falta de recursos adequados para o exercício da prática docente nestes ambientes virtuais. Acreditamos que possa estar centrado em um distanciamento do professor no que se refere às TD e na ocupação deste lugar tecnológico, neste cenário de possibilidades. Cabe ressaltar que a pandemia é, na verdade, um pano de fundo e o habitar 
desse mundo tecnológico agora se dá justamente por causa da situação em que nos encontramos.

Neste contexto, o habitar hedeggeriano quando endereçado ao professor e suas práticas de ensino com as TD solicita permanente reflexão sobre o tecnológico que está tão presente na sociedade atual, mas que ainda nos causa estranhamentos pelos desencontros que têm se mostrado. Solicita a necessidade de fazer-se presente com as TD, sobretudo neste momento de distanciamento social em que a pandemia aparece como um momento de abertura forçando-nos a habitar a educação por meio das tecnologias, ou que pelo menos consigamos habitar esses espaços de um modo mais legítimo ao fazer uso, de fato, das tecnologias como instrumento de modificação da realidade escolar.

A partir desse momento em que pensamos, estamos juntos daquela ponte lá e não junto a um conteúdo de representação armazenado em nossa consciência. Daqui podemos até mesmo estar bem mais próximos dessa ponte e do espaço que ela dá e arruma do que alguém que a utiliza diariamente como um meio indiferente de atravessar os espaços e, com eles, "o" espaço, já sempre encontraram um espaço na de-mora dos mortais. Os espaços abrem-se pelo fato de serem admitidos no habitar do homem (HEIDEGGER, 2008, p. 136).

As TD podem fazer parte do cotidiano do professor em seu trabalho pedagógico, criando uma sinergia entre as TD e o ensino da matemática, de forma não dissociada uma da outra. Assim, quando o professor pensar na tecnologia poderá estar habitando este lugar-tecnológico. Refletindo e voltando aos pensamentos de Heidegger, "quando começo a atravessar a sala em direção a saída, já estou lá na saída. Não me seria possível percorrer a sala se eu não fosse de tal modo que sou aquele que está lá” (HEIDEGGER, 2008, p. 136).

Quando as TD passam a fazer parte das práticas de ensino, do planejamento do professor e dos elementos presentes em seus encaminhamentos de ensino, as tecnologias já não deveriam causar estranhamento, pois fariam parte da rotina educacional, sejam elas virtuais ou não, tendo assim um ensino-da-matemática-com-as-TD. No caminho de habitar este lugar, abre-se possibilidade para outros questionamentos, outras reflexões para o uso da tecnologia no ensino da matemática, com vistas a uma educação tecnológica em ambientes virtuais.

O habitar, na obra heideggeriana, não se traduz em um abrigo, mas em um buscar, caminhar, permanecer, que se coloca em presença quando sai do tédio - acometido por uma vida utilitária mergulhado em atribuições que lhe ocupam de modo à entificá-lo, e que passa a se estranhar, a questionar o mundo e questionar-se no mundo (MOCROSKY; MONDINI; ORLOVSKI, 2018, p. $38)$. 
Estas são frestas abertas à novas interrogações que necessitam de outras reflexões acerca do habitar o mundo tecnológico, movendo o professor pela busca deste homemno-mundo e de como estas relações se desenvolvem na sociedade por meio da educação, sem perdemos de vista o que entendemos por educação. Em nossos estudos, assumimos a educação

[...] como cuidar, no sentido, de ajuda, de estar junto com o outro, de solicitude, para que a pre-sença seja liberada na direção a tornar-se sua cura, isto é, para que seja também na dimensão ontológica. É um estar-com de maneira atenta, não nos deixando banalizar pelo cotidiano em sua mesmice e nos afazeres das exigências públicas, quando se é todos e não se é ninguém, ao mesmo tempo [...] (BICUDO, 2011b, p. 91).

Assim, além de pensarmos em habitar o mundo tecnológico, no horizonte do cuidado que a educação nos exige, no sentido da escuta e do estar-junto-com-o-outro, necessitamos

[...] preocuparmo-nos com o ensino é ficar atentos às questões a respeito do para que esse ensino? Por que ensinar desse modo? Com quem vou efetuar as ações de ensinar? Onde eu e o outro as efetuamos? São preocupações com o que acontecerá em relação às possibilidades antevistas diante dos desdobramentos dessa ação interventiva, realizada com o outro (BICUDO, 2011b, p. 88).

Acreditamos nas possibilidades de um ensino de matemática que se paute no cuidado de estar-com-o-outro, um ensino que se ocupe e pre-ocupe com as práticas pedagógicas, e que promova o pertencimento do professor ao sentir-se habitando a tecnologia com vistas à aprendizagem.

\section{Algumas considerações}

Esse momento que estamos vivendo deixou muito claro que a ideia do habitar apresenta suas nuances, pois somos cientes de que os equipamentos existiam dentro da escola ou nos espaços de convivência do professor. Porém, o que se revelou é que o professor não vem sendo formado para atuar em ambientes virtuais, por meio de TD, mas que deveria estar nesse processo de formação, uma vez que partimos do pressuposto de que a formação é continuada.

Sabemos que o professor é livre para fazer suas escolhas metodológicas. O problema é que nessa nova conjuntura política-sanitária-educacional esse professor não está podendo fazer escolhas, pois tudo está sendo verticalizado. O desencontro professoraluno-tecnologia está acontecendo muito porque temos observado que alguns alunos estão muito à frente, justamente por tratar-se de um público que é designado como nativo digital, ou seja, é um público que já nasceu rodeado de tecnologia e, portanto, nós 
enquanto imigrantes digitais não temos muita coisa a fazer a não ser tentar acompanhar isso. Já o desencontro aluno-tecnologia tem se dado justamente pelo fato de que nem todo mundo tem acesso às TD, ou nem todo mundo tem acesso ao ambiente virtual.

Outra ressalva que fazemos é a de partimos de uma pré-concepção de que todos os professores, por estarem imersos nesse ambiente tecnológico, dominam a tecnologia. Este julgamento carrega um entendimento frágil e ingênuo, pois muitos mostram diariamente em nossos contextos vividos suas dificuldades tecnológicas. Por que compreendemos ser ingênuo este julgamento? Porque este declara que a formação tem um fim, no sentido de uma finalidade pré-estabelecida com a tecnologia. Porém, se pensarmos o encontro professor-tecnologia por esse viés, veremos que essa finalidade não existe, posto que a finalidade da formação é o caminho percorrido, é o formar-se, já que estamos entendendo por tecnológico o modo de as pessoas serem no mundo.

Nessa discussão, inserimos um debate embutido na ideia de acesso e de alcance, que permeiam a necessidade de cuidado e de escuta. As situações que estamos vivenciando em períodos de pandemia nos mostraram que há uma educação remota dividida em dois momentos: o primeiro caracterizado pelo acesso ou pelas dificuldades de acesso aos modos de ensino que foram tomados como solução paliativa para esse período; e o segundo que se caracteriza pelo não alcance daqueles que, mesmo tendo acesso, não se encontram nessa nova forma de ensino e de aprendizagem, visto a inexperiência com os ambientes virtuais que foram disponibilizados para o ensino. Em ambos os momentos o produto final tem sido a exclusão digital que se personifica na supressão do direito à educação.

Em todas essas situações se destacam a necessidade de cuidado para com o outro que é excluído por estar tornando-se translúcido e caminhando para a invisibilidade. Destacamos o clamor pela escuta daqueles que no silêncio de suas casas gritam pela efetivação do direito de ler o mundo enquanto pessoas alfabetizadas, por meio das suas diferentes formas de interpretação, fazendo uso dos mais diversos recursos. São pessoas que necessitam ser ouvidas para poderem externar o seu desejo de participação no mundo enquanto habitantes dessa casa que chamamos de Terra.

Acreditamos que não adianta perseguirmos um ideal de formação com tecnologia. A ideia é que venhamos habitar a tecnologia e a informação por aquilo que elas ressignificam na educação, já que para a formação de professores ela não é captável em um objeto. A crítica que fazemos, e que também não vemos resposta no horizonte, seria darmos conta de explicitar esse habitar como movimento existencial que é constituir e 
não apenas construir, é estranhar-se e sentir-se em abrigo ao fazer uso das TD para o ensino. Mas talvez esse seja apenas um jogo humano de incompletude do Ser em que estamos sempre em busca, não no sentido de perseguir algo para ter, mas de viver atentamente com.

O que estamos sentindo com essa vivência de ensinar em tempos de pandemia é que a matemática e as demais disciplinas perderam a centralidade. Ousamos trazer aqui nossas percepções, pois acreditamos que para a realização da educação, do ensinar e do aprender necessitamos estar com o outro, envolvidos com nossos estudantes e pares, cuidando e escutando estes de forma ocupada e preocupada com a existência das pessoas e que estas podem (e devem) constituir suas trajetórias de aprendizagem.

Muitas são as lições para educação em tempos de pandemia. Uma delas é que ensinar, seja no modo remoto ou presencial, é ser com outro. Portanto, a escola precisa aprender que o que a mantém em pé são as pessoas e que o cerne da educação é o estar junto. Estar-com é o que permite a estrutura escolar sustentando a formação de pessoas. O que essa situação pandêmica tem mostrado é que, quando o caos se instalou, voltamonos para fazer aquilo que é essencial na educação: estar-com-o-outro.

\section{Referências}

BATISTA, J. O. O professor que ensina matemática em ambiente tecnológico: a EaD em foco. 2016. Dissertação (Mestrado em Educação em Ciências e em Matemática) - Programa de Pós-Graduação em Educação em Ciências e em Matemática, Universidade Federal do Paraná, Curitiba, 2016.

BEZERRA, N.; VELOSO, A.; RIBEIRO, E. Ressignificando a prática docente: experiências em tempos de pandemia. Práticas Educativas, Memórias e Oralidades - Rev. Pemo, Fortaleza, v. 3, n. 2, p. 323917, jan. 2021.

BICUDO, M. A. V. Relação entre a Pesquisa em Educação Matemática e a Prática Pedagógica. Bolema, Rio Claro, v. 7, n. 8, p. 1-8, 1992

BICUDO, M. A. V. Realidade Virtual: uma abordagem filosófica. Ciências Humanas e Sociedade em Revista Seropédica, Rio de Janeiro, v. 32, n.1, p. 121-134, jan./jun. 2010.

BICUDO, M. A. V. Experiência e experiência vivida. In: TOURINHO, C. D. C; BICUDO, M. A. V. (org.). A fenomenologia: influxos e dissidências. Rio de Janeiro: Booklink, v. 1, $2011 \mathrm{a}$. p. 58-89.

BICUDO, M. A. V. A Fenomenologia do Cuidar na Educação. In: PEIXOTO, A. J.; HOLANDA, A. F. (org.). Fenomenologia do cuidado e do cuidar: perspectivas multidisciplinares. Curitiba: Juruá, 2011b. p. 85-91. 
BICUDO, M. A. V. A perplexidade: ser-com-o-computador e outras mídias. In: M. A. V. Bicudo (org.). Ciberespaço: Possibilidades que abre ao mundo da educação. São Paulo: Editora Livraria da Física, 2014. p.37-66.

BORBA, M. C; MALHEIROS, A. P. S.; AMARAL, R. B. Educação a Distância Online. 3. ed. Belo Horizonte: Autêntica Editora, 2011. (Tendências em Educação Matemática, 16).

BORBA, M. C.; PENTEADO, M. G. Informática e Educação Matemática. 5. ed. Belo Horizonte: Autêntica, 2016.

DILNOT, C.; O texto decisivo: para iniciar a leitura de "Construir, Habitar, Pensar". Tradução de Valéria Eugênia Garcia, Manoel A. L. Rodrigues Alves. Revista de pesquisa em arquitetura e urbanismo, São Paulo, v. 1, n. 9, p. 202-217, jan. 2009.

ENGELBRECHT, J.; BORBA, M. C.; LLINARES, S.; KAISER, G.. et. al. 2020 be remembered as the year in which education was changed? Zdm, [S.L.], v. 52, n. 5, p. 821-824, jul. 2020. Springer Science and Business Media LLC. http://dx.doi.org/10.1007/s11858-02001185-3.

FERREIRA, M. J. A. A expressão no ciberespaço: um voltar-se fenomenologicamente para o diálogo acerca de conteúdos matemáticos. 2014. Dissertação (Mestrado em Educação Matemática) - Instituto de Geociências e Ciências Exatas, Universidade Estadual Paulista "Júlio de Mesquita Filho", Rio Claro, 2014.

HEIDEGGER, M. Ser e Tempo. 12. ed. (parte I). Trad. Márcia de Sá Cavalcanti. Petrópolis: Vozes, 2002.

HEIDEGGER, M. Ser e Tempo. Tradução de F. Castilho. Campinas: Editora da Unicamp; Petrópolis: Editora Vozes, 2005.

HEIDEGGER, M. Ensaios e conferências. Tradução de Emmanuel Carneiro Leão, Gilvan Foge, Márcia Sá Cavalcante Schuback. 5. ed. Petrópolis: Vozes: Bragança Paulista: Universitária São Francisco, 2008.

HENRIQUE, T. COVID-19 e a internet (ou estou em isolamento social físico). Interfaces Científicas - Humanas e Sociais, Aracaju, v. 8, n. 3, p. 173-176, abr. 2020.

JESUS, M. P. A.; RIBEIRO, G. M. F.; Considerações sobre o habitar cotidiano no pensamento de Martin Heidegger. Existência e Arte: Revista Eletrônica do Grupo PET, São João Del-Rei, ano III, n. III, p. 1-7, jan./dez. 2007.

MARTINS, V.; ALMEIDA, J. Educação em tempos de pandemia no brasil: saberesfazeres escolares em exposição nas redes e a educação on-line como perspectiva. (C) Redoc, Rio de Janeiro, v. 4, n.2, p. 215-224, maio/ago. 2020.

MENDES, E.; O que é isto - habitar, em Martin Heidegger. Horizonte, Belo Horizonte, v.7, n.14, p. 195-199, jun. 2009.

MICHAELIS. Moderno dicionário da língua portuguesa. São Paulo: Melhoramentos. Disponível em: https://michaelis.uol.com.br/. Acesso em: 30 jan. 2021.

MOCROSKY, L. F. MONDINI, F. ORLOVSKY, N. A quem possa interessar. In: PAULO, R. M.; FIRME, I. C.; BATISTA, C. C. (org). Ser professor com tecnologias: sentidos e significados. São Paulo: Cultura Acadêmica, 2018. p. 43-58. 
MOCROSKY, L. F. MONDINI, F. ORLOVSKY, N. Familiarity-Strangeness: Movements on Actualization of a Project of Mathematics Teachers Technological Formation. In: BICUDO, M. A. V. (org.). Constitution and Production of Mathematics in the Cyberspace. New York: Springer, 2020. p. 159-172.

OBATA, J. Y.; MOCROSKI. F.; KALINKE, M. A. Tecnologia, educação e educação tecnológica: heranças e endereçamentos. Tear: Revista de Educação, Ciência e Tecnologia, Canoas, RS. v.7, n.1, p. 1-22. 2018.

Organização Mundial da Saúde (OMS). World Health Organization (WHO). Disponível em: https://www.who.int/eportuguese/countries/bra/pt/. Acesso em: 10 maio 2020.

PITTA, M. F.; Considerações preliminares sobre as noções de habitar e construir em Martin Heidegger e Peter Sloterdijk. Ekstasis: revista de hermenêutica e fenomenologia, Londrina, v.5, n.1, p. 61-71, 2016.

ROSA, M. Cyberformação com professores de matemática: interconexões com experiencias estéticas na cultura digital. In: ROSA, M.; BAIRRAL, M. A.; AMARAL, R. B. (org). Educação Matemática, Tecnologias Digitais e Educação a Distância: pesquisas contemporâneas. São Paulo: Editora Livraria da Física, 2015. p. 57-93.

SALDANHA, M. T.; KLAUTAU, P.; Habitar, construir e confiar: articulações entre Heidegger e Winnicott. Cad. Psicanál., Rio de Janeiro, v.38, n.35, p. 143-159, jul./dez. 2016.

SANTOS, C. de S. Educação escolar no contexto de pandemia: algumas reflexões. Gestão \& Tecnologia Faculdade Delta, Goiânia, ano IX, v. 1, p. 44-47, jan./jun. 2020.

SANTOS, J. P.; LIMA, R. V. G. Formação de professores em tempos de pandemia. Revista Projeção e Docência, Brasília, v.11, n 1, p. 01-25, 2020.

SARAMAGO, L. Entre a Terra e o Céu: a questão do habitar em Heidegger. O que nos faz pensar, Rio de Janeiro, v. 20, n.30, p.73-83, dez. 2011.

Recebido em: 30 de janeiro de 2021.

Aceito em: 11 de março de 2021. 